\title{
Erratum to: Atypical idiopathic inflammatory demyelinating lesions: prognostic implications and relation to multiple sclerosis
}

\author{
Mirja Wallner-Blazek • Alex Rovira - Massimo Filippi - Maria A. Rocca • \\ David H. Miller • Klaus Schmierer • Jette Frederiksen • Achim Gass • \\ Hugo Gama $\cdot$ Charles P. Tilbery $\cdot$ Antonio J. Rocha $\cdot$ José Flores • \\ Frederik Barkhof - Alexandra Seewann · Jacqueline Palace - Tarek Yousry • \\ Xavier Montalban $\cdot$ Christian Enzinger $\cdot$ Franz Fazekas
}

Published online: 7 March 2014

(c) Springer-Verlag Berlin Heidelberg 2014

Erratum to: J Neurol (2013) 260:2016-2022

DOI 10.1007/s00415-013-6918-y

The following co-author's (Massimo Filippi) Family name and (Maria A. Rocca) given name have been published incorrectly. The correct Family and given name should be Filippi and Maria A.

The online version of the original article can be found under doi:10.1007/s00415-013-6918-y.

M. Wallner-Blazek · C. Enzinger · F. Fazekas $(\bowtie)$

Department of Neurology, Medical University of Graz,

Auenbruggerplatz 22, 8036 Graz, Austria

e-mail: franz.fazekas@medunigraz.at

Present Address:

M. Wallner-Blazek

Neurologische Abteilung, Landesklinikum Wiener Neustadt,

Wiener Neustadt, Austria

\section{A. Rovira}

Department of Radiology, Hospital Universitari Vall d'Hebron, Barcelona, Spain

M. Filippi - M. A. Rocca

Neuroimaging Research Unit, Department of Neurology,

Scientific Institute and University, Ospedale San Raffaele,

Milan, Italy

D. H. Miller · K. Schmierer

Department of Neuroinflammation, Queen Square MS Centre, Institute of Neurology, University College London, London, UK
K. Schmierer

Blizard Institute, Centre for Neuroscience, Barts and The London School of Medicine and Dentistry, London, UK

\section{J. Frederiksen}

Department of Neurology, Glostrup Hospital, University of Copenhagen, Glostrup, Denmark

A. Gass

Universitätsklinikum Basel, Basel, Switzerland

A. Gass

Department of Neurology, University Hospital Mannheim, Mannheim, Germany

H. Gama · A. J. Rocha

Department of Radiology, Santa Casa de Misericordia de Sao Paulo, Sao Paulo, Brazil

\section{P. Tilbery}

Department of Neurology, Santa Casa de Misericordia de Sao Paulo, Sao Paulo, Brazil 
J. Flores

National Institute of Neurology, Mexico City, Mexico

F. Barkhof

Department of Radiology and Nuclear Medicine, VU University

Medical Centre, Amsterdam, The Netherlands

\section{A. Seewann}

Department of Neurology, VU University Medical Centre,

Amsterdam, The Netherlands

J. Palace

Department of Clinical Neurology, University of Oxford,

Oxford, UK

T. Yousry

Department of Radiology, Institute of Neurology, University

College London, London, UK

X. Montalban

Unitat de Neuroimmunologia Clinica, Hospital Universitari Vall

d'Hebron, Barcelona, Spain

C. Enzinger

Division of Neuroradiology, Department of Radiology, Medical

University of Graz, Graz, Austria 